\title{
Within-stem variations in mechanical properties of Melia azedarach planted in northern Vietnam
}

\author{
Doan Van Duong ${ }^{1,2} \cdot$ Junji Matsumura ${ }^{3}$
}

Received: 8 December 2017 / Accepted: 6 April 2018 / Published online: 2 May 2018

(C) The Japan Wood Research Society 2018

\begin{abstract}
Within-stem variations in the mechanical properties of 17-19-year-old Melia azedarach planted in two sites in northern Vietnam were examined by destructive and nondestructive methods. Wood samples were collected from 10, 50, and 90\% of the radial length from pith on both sides (North and South) at 0.3, 1.3, 3.3, 5.3, and $7.3 \mathrm{~m}$ heights above the ground. The mean values in whole trees of wood density (WD), modulus of rupture (MOR), modulus of elasticity (MOE), and dynamic modulus of elasticity $\left(E_{\mathrm{d}}\right)$ at $12 \%$ moisture content were $0.51 \mathrm{~g} / \mathrm{cm}^{3}, 78.58 \mathrm{MPa}, 9.26 \mathrm{GPa}$, and $10.93 \mathrm{GPa}$, respectively. Within the stem, the radial position was a highly $(p<0.001)$ significant source of variation in mechanical properties. MOR, MOE, and $E_{\mathrm{d}}$ increased from pith to bark. WD had a strong positive linear relationship with both MOR $(r=0.85, p<0.001)$ and $\mathrm{MOE}(r=0.73, p<0.001)$. This suggests that it is potentially possible to improve mechanical properties through controlling WD. MOR had also a strong linear relationship with $E_{\mathrm{d}}(r=0.84, p<0.001)$. This indicates that $E_{\mathrm{d}}$ is a good indicator to predicting the strength of wood if the density of measured element is known. Besides, the stress wave method used in this study provides relatively accurate information for determining the stiffness of Melia azedarach planted in northern Vietnam.
\end{abstract}

Keywords Melia azedarach $\cdot$ Mechanical properties $\cdot$ Nondestructive evaluation $\cdot$ Radial position

\section{Introduction}

Melia azedarach is an important fast-growing plantation species in Vietnam. It belongs to the Meliaceae family [1]. The wood has been used for manufacture agricultural implements, plywood, boxes, poles, tool handles, furniture, and light construction materials [2-4]. However, the published information is insufficient for a detailed quantification in mechanical properties and for the potential variation to be found within tree of Melia azedarach. A better understanding of the wood variability within tree is of value to both wood quality improvement and efficient wood processing

Junji Matsumura

matumura@agr.kyushu-u.ac.jp

1 Faculty of Agriculture, Graduate School of Bioresource and Bioenvironmental Sciences, Kyushu University, 6-10-1 Hakozaki, Higashi-ku, Fukuoka 812-8581, Japan

2 Faculty of Forestry, Thai Nguyen University of Agriculture and Forestry, Thai Nguyen, Vietnam

3 Laboratory of Wood Science, Faculty of Agriculture, Kyushu University, 6-10-1 Hakozaki, Higashi-ku, Fukuoka 812-8581, Japan and utilization. In a previous study [5], we reported that the Melia azedarach trees planted in site 2 (Son La provenance) were higher in wood specific gravity and fiber length and smaller in microfibril angle of the $S_{2}$ layer of cell wall than those planted in site 1 (Tuyen Quang provenance). This implies that mechanical properties on wood of Melia azedarach planted in site 2 may also be higher than those planted in site 1 . Therefore, this finding motivated us to examine within-stem variations and compare mechanical properties of Melia azedarach planted in two sites in northern Vietnam.

It is well known that wood quality assessment involves the consideration of wood density (WD) and mechanical properties [6]. WD is one of the most important properties of lignocellulosic materials due to its effect on strength, performance, and the general quality of the final products [7]. Besides, modulus of elasticity (MOE) and modulus of rupture (MOR) are also important properties for the use of wood as structural material. MOE is an indication of stiffness of board or structural member, while MOR is an indication of strength [8]. Therefore, the determination of mechanical properties (MOR and MOE) together with WD is important to understand their relationships. 
Currently, rapid and efficient methods for the determination of material properties are desired. Bucur [9] and Keunecke et al. [10] highlighted the benefits of the ultrasonic technique for the determination of the properties of wood, among which are the capability to test small specimens and the possibility of testing the same specimen several times due to the nondestructive nature of these measurements. Thus, if the structural timber can be classified by means of a nondestructive method, it is expected that the optimal utilization would be applied to each wood group.

Therefore, the main objective of this study was to quantify and estimate variations within stem and compare the mechanical properties of Melia azedarach planted in two sites in northern Vietnam. This study was also intended to determine the relationship between WD and mechanical properties; between the mechanical properties measured by destructive and nondestructive methods. Besides, the quality of timber produced from Melia azedarach in Vietnam was assessed based on their mechanical properties for grading purpose.

\section{Materials and methods}

\section{Sampling}

Six trees around 17-19 years old (ring count at $15 \mathrm{~cm}$ above the ground) were chosen basing on straight trunks, normal branching, and no signs of any diseases or pest symptoms and felled in August 2016 from two state-owned plantations in Vietnam. The trees were planted at a stand density of 830 trees per hectare at spacing of $4 \mathrm{~m} \times 3 \mathrm{~m}$ from seedlings produced by seeds from natural forests located near each site. As described in a previous paper [5], the location and detail information of the two sites are given in Table 1. The trees were felled through cutting their stems at $15 \mathrm{~cm}$ above the soil level. $50 \mathrm{~cm}$ long logs were taken at different height levels $(0.3,1.3,3.3,5.3$, and $7.3 \mathrm{~m}$ heights from above the ground). The north and south sides of each tree were marked before felling. Sample trees were the same as those used in

Table 1 General characteristics of the study sites [5]

\begin{tabular}{lll}
\hline Description & Site 1: Northeast & Site 2: Northwest \\
\hline Province & Tuyen Quang & Son La \\
Latitude & $22^{\circ} 17^{\prime} 01^{\prime \prime} \mathrm{N}$ & $20^{\circ} 56^{\prime} 18^{\prime \prime} \mathrm{N}$ \\
Longitude & $105^{\circ} 19^{\prime} 22^{\prime \prime} \mathrm{E}$ & $104^{\circ} 26^{\prime} 25^{\prime \prime} \mathrm{E}$ \\
Altitude $(\mathrm{m})$ & 112 & 434 \\
Mean rainfall $\left(\mathrm{mm} \mathrm{year}^{-1}\right)$ & 2000 & 1300 \\
Mean temperature $\left({ }^{\circ} \mathrm{C}\right)$ & 23.4 & 24 \\
Soil origin & Calcisols & Ferralsols \\
\hline
\end{tabular}

the previous study on variation in intrinsic wood properties (Table 2) [5].

From each log, specimens $(20 \times 20 \times 320 \mathrm{~mm}$, radial $\times$ tangential $\times$ longitudinal) were cut at three distances from pith $(10,50$, and $90 \%$ of the radial length) on both sides (North and South). MOR and MOE were assessed in accordance with Japanese Industrial Standards (JIS Z2101) [11]. The total number of small clear wood specimens was 180 . The specimens were conditioned in a room at a constant temperature $\left(20^{\circ} \mathrm{C}\right)$ and relative humidity $(60 \%)$ to constant weight. The average moisture content of the test pieces after this state was approximately $12 \%$.

\section{WD and dynamic modulus of elasticity $\left(E_{\mathrm{d}}\right)$}

Before measuring the MOR and MOE by destructive method, WD and $E_{\mathrm{d}}$ were measured for each specimen. WD was obtained as a percentage of the wood weight per wood volume. $E_{\mathrm{d}}$ was measured by a stress wave method (Fakopp machine). The Fakopp device measures the time of acoustic wave propagation through timber element, including the length of coaxial connections of probes. The acoustic signal is created by a hammer strike on the acoustic probe. The velocity of acoustic wave propagation is a ratio of length of specimen per propagation time. $E_{\mathrm{d}}$ in the direction parallel to grain was then determined by a simple relation:

$E_{\mathrm{d}}=\rho \cdot v^{2}$

where $E_{\mathrm{d}}$ is dynamic modulus of elasticity (GPa); $\rho$ is wood density $\left(\mathrm{kg} / \mathrm{cm}^{3}\right)$; and $\nu$ is velocity of acousitic wave propagation $(\mathrm{m} / \mathrm{s})$.

\section{MOR and MOE}

Specimens were subjected to bending test using Instron Tester over a span length of $280 \mathrm{~mm}$. Load was applied to the center of the specimen at a constant speed of $5 \mathrm{~mm}$ per minute. MOR and MOE were calculated as

Table 2 Age, diameter at breast height, and total stem height of sampled Melia azedarach trees [5]

\begin{tabular}{lllll}
\hline Site & Tree no. & Age $^{\mathrm{a}}$ (years) & DBH $(\mathrm{cm})$ & $H(\mathrm{~m})$ \\
\hline Site 1 & 1 & 18 & 32.5 & 19.6 \\
& 2 & 19 & 32.2 & 21.1 \\
& 3 & 17 & 32.5 & 21.4 \\
Site 2 & 4 & 18 & 33.8 & 20.1 \\
& 5 & 18 & 32.2 & 19.1 \\
& 6 & 17 & 29.9 & 21.4 \\
\hline
\end{tabular}

$D B H$ diameter at breast height (at $1.3 \mathrm{~m}$ above the ground), $H$ tree height

${ }^{a}$ Measured by ring counting at the $15 \mathrm{~cm}$ above the ground 
$\mathrm{MOR}=\frac{3 P L}{2 b h^{2}}$

$$
\mathrm{MOE}=\frac{P_{1} L^{3}}{4 d_{1} b h^{3}}
$$

where MOR is modulus of rupture; MOE is modulus of elasticity; $P$ is maximum load $(\mathrm{N}) ; P_{1}$ is load at the limit of proportionality $(\mathrm{N}) ; L$ is span length $(\mathrm{mm}) ; b$ is width of the specimen $(\mathrm{mm}) ; h$ is thickness of the specimen $(\mathrm{mm})$; and $d_{1}$ is the deflection at the limit of proportionality (mm).

\section{Data analysis}

Analysis of variance (ANOVA) for all wood mechanical properties (MOR, MOE, and $E_{\mathrm{d}}$ ) was performed according to the model shown in Table 3 to test the significance of site, tree, height level, and radial position effects. Trees were considered as random effects, and the other sources of variation as fixed effects. Variance components for the sources of variation were also estimated. Average WD, MOR, MOE, and $E_{\mathrm{d}}$ were computed for each radial position, stem height, site and for total sites. Besides, the differences among radial and height positions within stem were examined by Tukey-Kramer HSD test. Statistical analysis was performed using R software version 3.2.3.

\section{Grade yield}

Grade yield for the specimens was checked using the grading standard of mechanical properties of timbers from Southeast Asia and Pacific regions by Forestry and Forest Products Research Institute (FFPRI) in Japan (Table 4) [12].

Table 3 Model used in the analysis of variance

\begin{tabular}{ll}
\hline No. & Source of variation \\
\hline 1 & Site $(S)$ \\
2 & Tree/site $(T / S)$ \\
3 & Height level $(L)$ \\
4 & $L \times S$ \\
5 & $L \times T / S$ \\
6 & Radial position $(P)$ \\
7 & $P \times S$ \\
8 & $P \times T / S$ \\
9 & $P \times L$ \\
10 & $P \times L \times S$ \\
11 & $P \times L \times T / S$ \\
12 & Residuals \\
\hline
\end{tabular}

Table 4 Grading standard of mechanical properties of timber from Southeast Asia and Pacific regions by Forestry and Forest Products Research Institute (FFPRI) (1975)

\begin{tabular}{lll}
\hline Grade & MOR $(\mathrm{MPa})$ & MOE $(\mathrm{GPa})$ \\
\hline I & $\leq 58.8$ & $\leq 7.4$ \\
II & $58.9-82.4$ & $7.5-10.3$ \\
III & $82.5-106.9$ & $10.4-13.2$ \\
IV & $107.0-130.4$ & $13.3-16.2$ \\
V & $\geq 130.5$ & $\geq 16.3$ \\
\hline
\end{tabular}

Units for MOR $\left(\mathrm{kg} / \mathrm{cm}^{2}\right)$ and MOE $\left(10^{3} \mathrm{~kg} / \mathrm{cm}^{2}\right)$ in original material were, respectively, converted to $\mathrm{MPa}$ and $\mathrm{GPa}$ for convenience in allocation the values in this study

MOR modulus of rupture, MOE modulus of elasticity

\section{Results and discussion}

\section{WD and mechanical properties}

Table 5 shows the mean WD and mechanical properties each radial position, stem height, site and for total sites of Melia azedarach planted in the northern Vietnam. The overall WD, MOR, MOE, and $E_{\mathrm{d}}$ were $0.51 \mathrm{~g} / \mathrm{cm}^{3}, 78.58 \mathrm{MPa}, 9.26 \mathrm{GPa}$, and $10.93 \mathrm{GPa}$, respectively. The results are consistent with those published for Melia azedarach planted in southeastern Vietnam [13].

Table 6 shows the results obtained for the analysis of variance made for each mechanical property, regarding the statistical significance and proportion of explained variation for the different sources of variation. The residual effect was responsible for $7.53-15.4 \%$ of the total variation, and it is due to other factors that were not taken into account in this experimental design.

Within tree, the variation of mechanical properties with height was very small and without statistical significant (Table 6). In radial direction, MOR, MOE, and $E_{\mathrm{d}}$ increased gradually from 10 to $90 \%$ of the radial length from pith and this trend was consistent in both sites (Fig. 1). Radial position is the most important and highly significant source of variation in mechanical properties, explaining 55.31, 30.93, and $37.53 \%$ of the total variation of the MOR, MOE, and $E_{\mathrm{d}}$, respectively (Table 6). The present results are in line with those of Machado et al. [14] who reported that height level was not a significant source, while radial position was highly significant source of variation for the mechanical properties on Acacia melanoxylon $\mathrm{R}$. Br. Variation along the radial direction is the best known and most studied withintree variability in wood, which is generally reflected as radial pattern of change in wood characteristics. The radial change in wood properties varies in magnitude and type in different species [15-17]. The radial variation in mechanical properties of other hardwood species such as Swietenia macrophylla Roxb [6], Tectona grandis [18], and Nauclea 
Table 5 Variations of wood density (WD), modulus of rupture (MOR), modulus of elasticity (MOE), and dynamic modulus of elasticity $\left(E_{\mathrm{d}}\right)$ within stem and between sites of Melia azedarach

\begin{tabular}{llllllr}
\hline Variable & Description & $n$ & WD $\left(\mathrm{g} / \mathrm{cm}^{3}\right)$ & MOR $(\mathrm{MPa})$ & MOE $(\mathrm{GPa})$ & \multicolumn{1}{c}{$E_{\mathrm{d}}(\mathrm{GPa})$} \\
\hline Radial direction (\%) & 10 & 60 & $0.44 \pm 0.01^{\mathrm{c}}$ & $54.64 \pm 2.55^{\mathrm{c}}$ & $7.81 \pm 0.22^{\mathrm{c}}$ & $9.15 \pm 0.24^{\mathrm{c}}$ \\
& 50 & 60 & $0.52 \pm 0.01^{\mathrm{b}}$ & $82.18 \pm 2.23^{\mathrm{b}}$ & $9.55 \pm 0.20^{\mathrm{b}}$ & $11.20 \pm 0.22^{\mathrm{b}}$ \\
& 90 & 60 & $0.57 \pm 0.01^{\mathrm{a}}$ & $98.94 \pm 1.48^{\mathrm{a}}$ & $10.41 \pm 0.21^{\mathrm{a}}$ & $12.45 \pm 0.23^{\mathrm{a}}$ \\
Stem height (m) & 7.3 & 36 & $0.51 \pm 0.01^{\mathrm{a}}$ & $77.58 \pm 4.20^{\mathrm{a}}$ & $9.71 \pm 0.32^{\mathrm{a}}$ & $11.25 \pm 0.38^{\mathrm{a}}$ \\
above the ground & 5.3 & 36 & $0.49 \pm 0.01^{\mathrm{a}}$ & $74.70 \pm 4.01^{\mathrm{a}}$ & $8.87 \pm 0.35^{\mathrm{a}}$ & $10.76 \pm 0.40^{\mathrm{a}}$ \\
& 3.3 & 36 & $0.51 \pm 0.01^{\mathrm{a}}$ & $78.78 \pm 4.31^{\mathrm{a}}$ & $9.52 \pm 0.31^{\mathrm{a}}$ & $11.25 \pm 0.36^{\mathrm{a}}$ \\
& 1.3 & 36 & $0.50 \pm 0.01^{\mathrm{a}}$ & $81.28 \pm 4.05^{\mathrm{a}}$ & $9.36 \pm 0.29^{\mathrm{a}}$ & $10.86 \pm 0.34^{\mathrm{a}}$ \\
& 0.3 & 36 & $0.52 \pm 0.01^{\mathrm{a}}$ & $80.57 \pm 4.07^{\mathrm{a}}$ & $8.84 \pm 0.34^{\mathrm{a}}$ & $10.55 \pm 0.38^{\mathrm{a}}$ \\
Site & 1 & 90 & $0.50 \pm 0.01^{\mathrm{b}}$ & $66.20 \pm 2.55^{\mathrm{b}}$ & $8.25 \pm 0.19^{\mathrm{b}}$ & $9.73 \pm 0.21^{\mathrm{b}}$ \\
& 2 & 90 & $0.52 \pm 0.01^{\mathrm{a}}$ & $90.97 \pm 1.90^{\mathrm{a}}$ & $10.27 \pm 0.16^{\mathrm{a}}$ & $12.13 \pm 0.18^{\mathrm{a}}$ \\
Mean & & 180 & $0.51 \pm 0.01$ & $78.58 \pm 1.84$ & $9.26 \pm 0.15$ & $10.93 \pm 0.17$ \\
\hline
\end{tabular}

Mean values are followed by standard errors

$n$ number of wood specimen

${ }^{\mathrm{a}, \mathrm{b}, \mathrm{c}}$ Means with different superscript within a column significantly differ $(p<0.05)$

\begin{tabular}{|c|c|c|c|c|c|c|c|}
\hline \multirow[t]{2}{*}{ Source of variation } & \multirow[t]{2}{*}{$d f$} & \multicolumn{2}{|l|}{ MOR } & \multicolumn{2}{|l|}{ MOE } & \multicolumn{2}{|l|}{$E_{\mathrm{d}}$} \\
\hline & & $p$ value & $\operatorname{Var}(\%)$ & $p$ value & $\operatorname{Var}(\%)$ & $p$ value & $\operatorname{Var}(\%)$ \\
\hline Site $(S)$ & 1 & 0.001 & 25.43 & 0.001 & 26.78 & 0.001 & 29.15 \\
\hline Tree/site $(T / S)$ & 4 & 0.862 & 0.55 & 0.013 & 5.12 & 0.001 & 6.78 \\
\hline Height level $(L)$ & 4 & 0.717 & 0.91 & 0.103 & 3.18 & 0.432 & 1.55 \\
\hline$L \times S$ & 4 & 0.974 & 0.21 & 0.618 & 1.08 & 0.001 & 0.57 \\
\hline$L \times T / S$ & 16 & 0.996 & 2.24 & 0.298 & 7.08 & 0.843 & 3.90 \\
\hline Radial position $(P)$ & 2 & 0.001 & 55.31 & 0.001 & 30.93 & 0.028 & 37.53 \\
\hline$P \times S$ & 2 & 0.001 & 2.09 & 0.209 & 0.76 & 0.199 & 0.61 \\
\hline$P \times T / S$ & 8 & 0.031 & 1.62 & 0.400 & 1.80 & 0.001 & 4.39 \\
\hline$P \times L$ & 8 & 0.150 & 1.19 & 0.869 & 1.50 & 0.923 & 0.61 \\
\hline$P \times L \times S$ & 8 & 0.933 & 0.29 & 0.864 & 0.90 & 0.766 & 0.95 \\
\hline$P \times L \times T / S$ & 32 & 0.511 & 2.62 & 0.483 & 5.47 & 0.927 & 2.57 \\
\hline Residuals & 90 & & 7.53 & & 15.4 & & 11.40 \\
\hline
\end{tabular}

$M O R$ modulus of rupture, $M O E$ modulus of elasticity, $E_{\mathrm{d}}$ dynamic modulus of elasticity, $d f$ degrees of freedom, Var variance (\%)
Table 6 Variance components for mechanical properties of Melia azedarach the wood properties of the same species are due to different genotypes and ecological conditions of sites such as altitude, precipitation, temperature, soil, water, and nutrients. These two factors affect both the growth and development of trees [20]. Genetic structure is the main source of change of wood's properties, while ecological conditions of site directly or indirectly affect on the development and fertility, body form, and height of tree. Thus, in the present study, the significant difference in all mechanical properties between site 1 and site 2 may be contributed by the differences in altitude, mean annual rainfall, and soil types between two sites (Table 1). However, further experiments will be needed to determine genetic effect on variation in mechanical properties for Melia azedarach planted in northern Vietnam. 

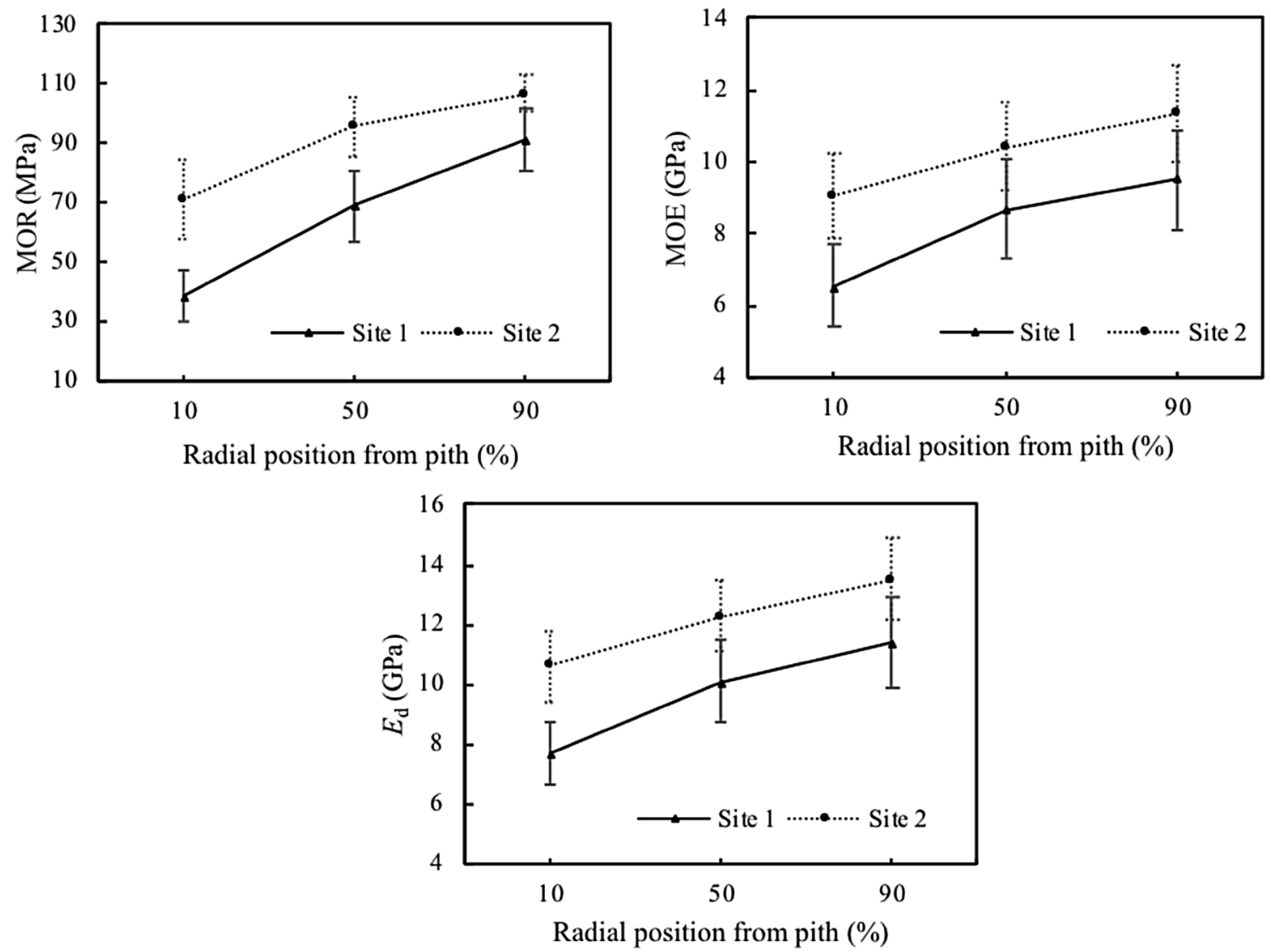

Fig. 1 Radial variation of modulus of rupture (MOR), modulus of elasticity (MOE), and dynamic modulus of elasticity ( $\left.E_{\mathrm{d}}\right)$ by sites for Melia azedarach (bars: mean standard deviation)

\section{Correlation of WD with mechanical properties}

Relationships between WD and mechanical properties are presented in Fig. 2 and Table 7. The results showed that WD had significant positive linear relationships at the 0.001 confidence level with MOR ( $r=0.93$ for site $1, r=0.84$ for site 2) and MOE ( $r=0.79$ for site $1, r=0.72$ for site 2$)$. This implies that WD can be used as a parameter for predicting mechanical properties. Therefore, improving WD which can be obtained by tree breeding programs, growth conditions, or section for high wood density parts, etc. would have a positive impact on mechanical properties of Melia
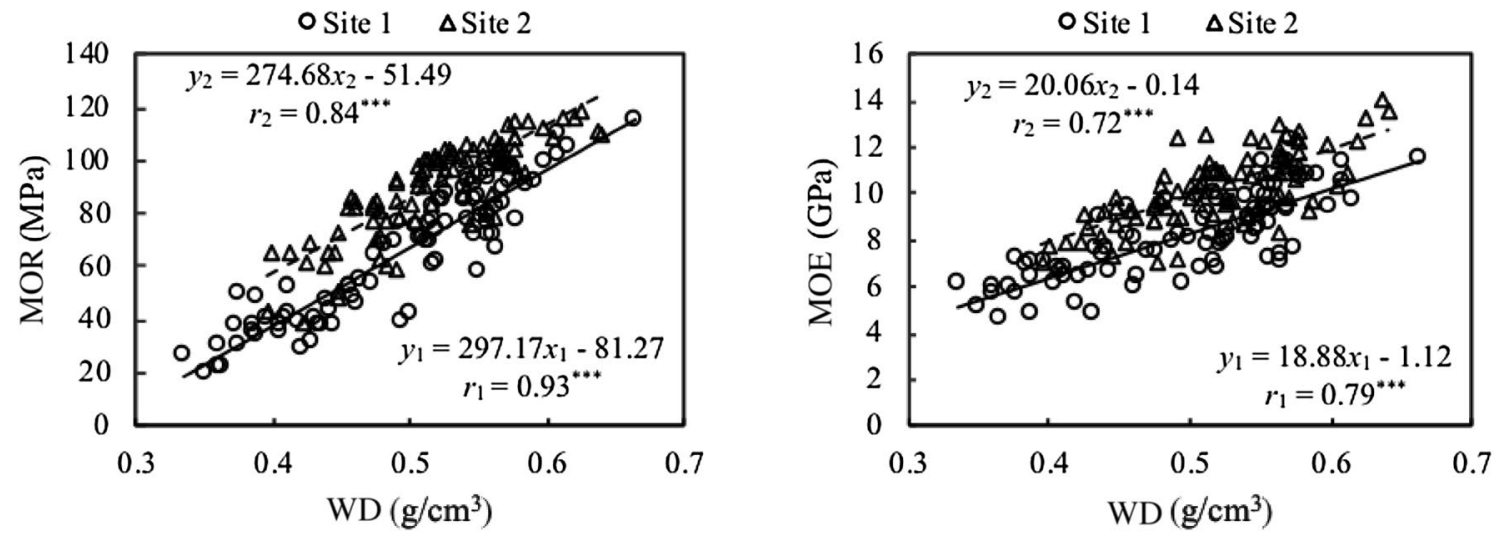

Fig. 2 Relationship between wood density (WD) and modulus of rupture (MOR); and WD and modulus of elasticity (MOE) for Melia azedarach in two sites (solid and dash lines are linear relationships for site 1 and site 2 , respectively. Triple asterisks: $p<0.001$ ) 

wood density (WD) and mechanical properties; dynamic $\left(E_{\mathrm{d}}\right)$ and static (MOR, MOE) properties for each site and combined sites of Melia azedarach
Table 7 Relationship between

\begin{tabular}{|c|c|c|c|c|c|c|c|}
\hline \multirow[t]{3}{*}{ Site } & \multicolumn{7}{|c|}{ Linear regression model $y=a x+b$} \\
\hline & \multirow{2}{*}{$\begin{array}{l}\text { Mechanical } \\
\text { properties }\end{array}$} & \multicolumn{3}{|l|}{ WD } & \multicolumn{3}{|l|}{$E_{\mathrm{d}}$} \\
\hline & & $a$ & $b$ & $r$ & $a$ & $b$ & $r$ \\
\hline \multirow[t]{3}{*}{ Site 1} & MOR & 297.17 & -81.27 & $0.93 * * *$ & 9.80 & -29.19 & $0.82 * * *$ \\
\hline & MOE & 18.88 & -1.12 & $0.79 * * *$ & 0.83 & 0.22 & $0.93 * * *$ \\
\hline & $E_{\mathrm{d}}$ & 23.08 & -1.72 & $0.86 * * *$ & - & - & - \\
\hline \multirow[t]{3}{*}{ Site 2} & MOR & 274.68 & -51.49 & $0.84 * * *$ & 7.46 & 0.49 & $0.72 * * *$ \\
\hline & MOE & 20.06 & -0.14 & $0.72 * * *$ & 0.76 & 1.06 & $0.85 * * *$ \\
\hline & $E_{\mathrm{d}}$ & 25.72 & -1.20 & $0.82 * * *$ & - & - & - \\
\hline \multirow[t]{3}{*}{ Combined sites } & MOR & 312.25 & -79.86 & $0.85^{* * *}$ & 9.24 & -22.45 & $0.84 * * *$ \\
\hline & MOE & 21.29 & -1.55 & $0.73 * * *$ & 0.81 & 0.41 & $0.92 * * *$ \\
\hline & $E_{\mathrm{d}}$ & 26.35 & -2.44 & $0.79 * * *$ & - & - & - \\
\hline
\end{tabular}

$M O R$ modulus of rupture, $M O E$ modulus of elasticity, $E_{\mathrm{d}}$ dynamic modulus of elasticity, $r$ correlation coefficient

$* * * p<0.001$

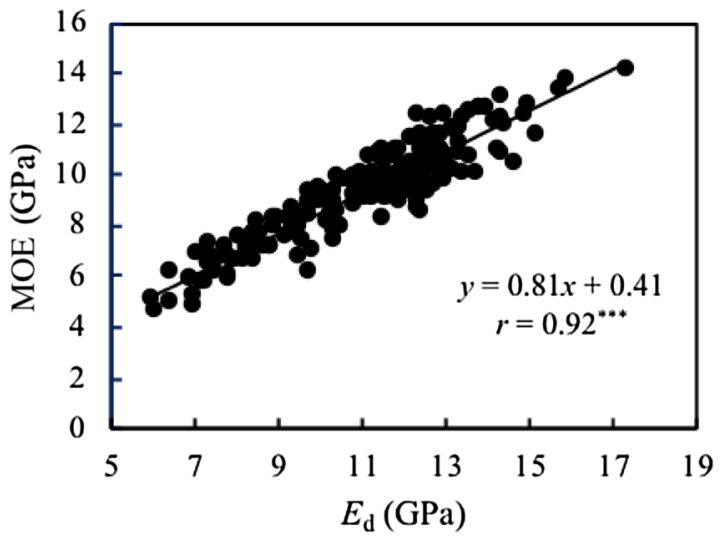

Fig. 3 Correlation between moduli of elasticity measured by acoustic method and destructive test for combined sites of Melia azedarach (triple asterisk: $p<0.001$ )

azedarach. Positive linear relationships between WD and mechanical properties were also found on other hardwood species such as Tectona grandis [18], Eucalyptus tereticornis [21], and Acacia melanoxylon [14, 22]. The $r$ values of WD and mechanical properties for site 1 are slightly higher than those for site 2 . This could be caused by the differences in growth conditions such as altitude, mean annual rainfall, and soil types between two sites.

\section{Correlation between moduli of elasticity}

The correlation coefficient between the moduli of elasticity of the acoustic method and the destructive test for the combined sites was very high $(r=0.92, p<0.001)$ (Fig. 3). Similar results were also reported by different researchers for both structural timber and small specimen [23-27]. Widmann [23] and Johansson et al. [24] found high coefficient of correlation between $E_{\mathrm{d}}$ and MOE ( $r=0.94$ and 0.92 ) for beech and spruce, respectively. Sales et al. [25] and Vazquez et al. [26] also reported a high correlation between $E_{\mathrm{d}}$ measured by ultrasonic technique and static modulus of destructive test on structural lumber of Goupia glabra and Castanea sativa Mill., respectively. The strong correlation coefficient between MOE and $E_{\mathrm{d}}(r=0.91)$ for the combined species of small clear specimens [27] also supports the findings of the present study. Therefore, the present result indicated that the stress wave method used in this study provided relatively accurate information for MOE of Melia azedarach planted in northern Vietnam, if the density of measured element is known.

However, the value of MOE was measured by destructive test which best defines class of timber, is usually lower than the value of $E_{\mathrm{d}}$ measured by acoustic method. In present study, the average value of MOE is lower than that of $E_{\mathrm{d}}$ about $15.28 \%$ or $1.67 \mathrm{GPa}$ (Table 5). This is confirmed by other reports in literature. Wang et al. [27] showed the difference between dynamic and static modulus of elasticity observed for small clear specimens of Western hemlock 20.74\% (1.93 GPa) and Sitka spruce 28.78\% (2.76 GPa). Posta et al. [28] confirmed that the value of $E_{\mathrm{d}}$ measured by Fakopp is higher than the value of MOE about $27 \%$ for Norway spruce.

\section{Prediction of bending strength}

MOE is closely related to MOR. It could be said that it is the best indicator of MOR, and thus classes of timber [28]. The results of relationship between moduli of elasticity and strength are presented in Fig. 4 and Table 7. The not only for each site, but also for combined sites between bending strength and moduli of elasticity detected by both results revealed that there were high correlation coefficients 

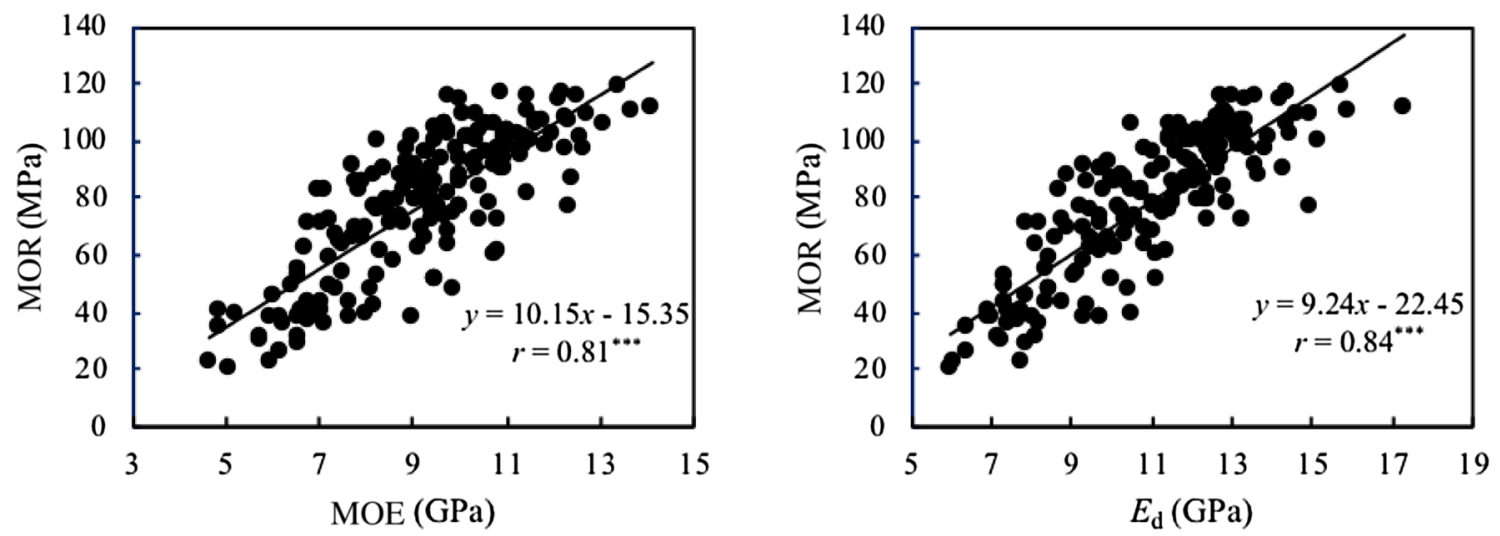

Fig. 4 Relationship between modulus of rupture (MOR) and modulus of elasticity (MOE); and MOR and dynamic modulus of elasticity $\left(E_{\mathrm{d}}\right)$ for combined sites of Melia azedarach (triple asterisk: $p<0.001$ )

destructive test and acoustic method. The $r$ values of MOR with MOE and $E_{\mathrm{d}}$ at the 0.001 confidence level for the combined sites are 0.81 and 0.84 , respectively (Fig. 4). This showed that $E_{\mathrm{d}}$ is a good indicator to predicting the strength of Melia azedarach wood. The results confirm the findings from the literature. Posta et al. [28] reported the relationship between MOR and MOE $(r=0.92)$ and between MOR and $E_{\mathrm{d}}(r=0.81)$ on Norway spruce laths. Wang et al. [27] presented good correlation coefficients between MOR and $E_{\mathrm{d}}(r=0.68$ for Western hemlock, $r=0.69$ for Sitka spruce) of small clear specimens. The positive relationship between MOR and $E_{\mathrm{d}}$ on Brazilian hardwood [29] also supports the findings of the present study.

\section{Grade yield of mechanical properties}

Figure 5 shows the grade yield for both MOR and MOE using grading standard of mechanical properties of timbers from Southeast Asia and Pacific regions (FFPRI, 1975). The grade yield for MOR in site 1 was the highest for grade I, followed by grade II and III. The grade IV was the lowest. The highest frequency of specimens for MOR in site 2 belonged to grade III, followed by grades II and IV. Grade I was the lowest. There was no grade yield of MOR in grade $\mathrm{V}$ for both sites. MOE for Melia azedarach grown in site 1 can be allocated mainly in to grades I and II while that in site 2 can be allocated mainly in to grades II and III. Based on results in Table 5 and Fig. 5, wood for Melia azedarach grown in site 1 (Tuyen Quang provenance) can be allocated into grade II while that in site 2 (Son La provenance) can be allocated in grade III using grading standard of mechanical properties of timber from Southeast Asia and Pacific regions.

It is well known that wood property is closely related to its structure. Relationship between structure and property has been of interest to wood scientists [30]. The previous researchers $[15,30,31]$ reported that wood with longer fiber length and lower microfibril angle has higher specific gravity and mechanical properties for some hardwood species. In the present study, together with higher
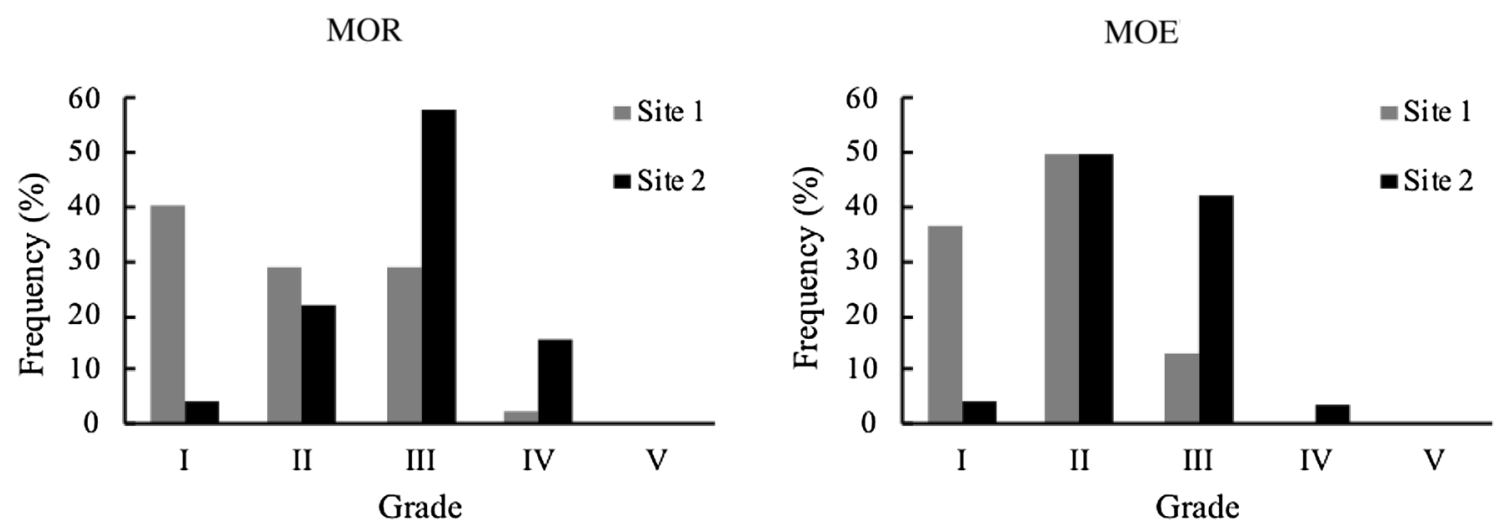

Fig. 5 Specimen grade allocation in terms of modulus of rupture (MOR) and modulus of elasticity (MOE) for both sites according to grading standard of mechanical properties of timbers from Southeast Asia and Pacific regions by FFPRI (1975) 
specific gravity, longer fiber length, and lower microfibril angle [5], Melia azedarach trees planted in site 2 also had higher mechanical properties than trees planted in site1. This implies that site 2 or any other location with similar environmental conditions (soil, rainfall, temperature, and altitude) to site 2 should be preferred for establishment of Melia azedarach plantations in northern Vietnam. In the future, we will investigate and clarify the effect of fiber length and microfibril angle on the within-tree variation in mechanical properties of Melia azedarach plantations in northern Vietnam.

The common steps in establishing grades for lumber are: testing of small clear specimens according to guidelines, establishing strength values and allowable properties, establishing visual grading rules, and lastly verifying grades using in-grade testing [32]. This research has established the first step in assigning allowable mechanical properties for Melia azedarach grown in northern Vietnam. This will help in assignment of standard grades that will ensure the efficient utilization of Melia azedarach timber in Vietnam.

\section{Conclusions}

This research has clarified within-stem variations in mechanical properties (MOR, MOE, and $E_{\mathrm{d}}$ ) of Melia azedarach grown in northern Vietnam. Within tree, the mechanical variation with height was very small and without statistical significant. In radial direction, MOR, MOE, and $E_{\mathrm{d}}$ increased from pith to bark and radial position is the most important and highly significant source of variation in mechanical properties. The average MOR, MOE, and $E_{\mathrm{d}}$ on wood of Melia azedarach planted in site 2 are higher than those planted in site 1 . WD had a strong positive linear relationship with mechanical properties. This suggests that controlling WD would have a positive impact on mechanical properties. The average value of MOE is lower than that of $E_{\mathrm{d}}$ about $15.28 \%$ or $1.67 \mathrm{GPa}$. High coefficient of correlation was found between $E_{\mathrm{d}}$ measured by stress wave method and MOE measured by destructive test. This suggests that the stress wave method used in this study provides relatively accurate information for MOE. Besides, MOR of Melia azedarach can be predicted by nondestructive technique, if the density of measured element is known. Furthermore, the present results are a foundation that will provide a technical basis for the machine grading of Melia azedarach timber in northern Vietnam.

Acknowledgements The first author was funded by Vietnam government for a Doctor course at Graduate School of Bioresource and Bioenvironmental Sciences, Kyushu University, Fukuoka, Japan.

\section{Compliance with ethical standards}

Conflict of interest The authors declare no conflict of interest.

\section{References}

1. Venson I, Guzman JAS, Talavera FJF, Richter HG (2008) Biological, physical and mechanical wood properties of Paraiso (Melia azedarach) from a roadside planting at Huaxtla, Jalisco, Mexico. J Trop For Sci 20(1):38-47

2. EL-Juhany LI (2011) Evaluation of some wood quality measures of eight-year-old Melia azedarach trees. Turk J Agric For $35: 165-171$

3. Nghia NH (2007) Atlas of Vietnam's forest tree species. Agric Publ House 1:242

4. Harrison NA, Boa E, Carpio ML (2003) Characterization of phytoplasmas detected in Chinaberry trees with symptoms of leaf yellowing and decline in Bolivia. Plant Pathol 52:147-157

5. Duong DV, Missanjo E, Matsumura J (2017) Variation in intrinsic wood properties of Melia azedarach L. planted in northern Vietnam. J Wood Sci 63(6):560-567

6. Anoop EV, Jijeesh CM, Sindhumathi CR, Jayasree CE (2014) Wood physical, anatomical and mechanical properties of big leaf Mahogany (Swietenia macrophylla Roxb) a potential exotic for South India. Res J Agric For Sci 2(8):7-13

7. Zobel BJ, Van Buijtenen JP (1989) Wood variation, its causes and control. Springer, Heidelberg

8. Johnson GR, Gartner BL (2006) Genetic variation in basic density and modulus of elasticity of coastal Douglas-fir. Tree Genet Genomes 3:25-33

9. Bucur V (1983) An ultrasonic method for measuring the elastic constants of wood increment cores bored from living trees. Ultrasonics 21:116-126

10. Keunecke D, Sonderegger W, Pereteanu K, Luthi T, Niemz P (2007) Determination of young's and shear moduli of common yew and Norway spruce by means of ultrasonic waves. Wood Sci Technol 41:309-327

11. JIS Z2101:1994 (2000) Methods of test for woods (in Japanese). Japanese Standard Association, Tokyo

12. Forestry and Forest Products Research Institute (FFPRI) (1975) The properties of tropical woods 21: evaluation of wood properties and wood processing suitabilities of timber from Southeast Asia and the Pacific regions. Bull Gov For Exp Stn 277:87-130

13. Hien LT, Ban DV, Kim NT (2012) Physical and mechanical characteristics and uses of some production forest species in southeastern Vietnam (in Vietnamese with English summary). Dissertation, Forest Science Institute of Vietnam

14. Machado JS, Louzada JL, Santos AJA, Nunes L, Anjos O, Rodrigues J, Simoes RMS, Pereira H (2014) Variation of wood density and mechanical properties of blackwood (Acacia melanoxylon $\mathrm{R}$. Br.). Mater Des 56:975-980

15. Uetimane JE, Ali AC (2011) Relationship between mechanical properties and selected anatomical features of ntholo (Pseudolachnostylis maprounaefolia). J Trop For Sci 23(2):166-176

16. Ishiguri F, Hiraiwa T, Lizuka K, Yokota S, Priadi D, Sumiasri N, Yoshizawa N (2009) Radial variation of anatomical characteristics in Paraserianthes falcataria planted in Indonesia. IAWA J 30(3):343-352

17. Ishiguri F, Wahyudi I, Takeuchi M, Takashima Y, Iizuka K, Yokota S, Yoshizawa N (2011) Wood properties of Pericopsis mooniana grown in a plantation in Indonesia. J Wood Sci $57: 241-246$ 
18. Izekor DN, Fuwape JA, Oluyege AO (2010) Effects of density on variations in the mechanical properties of plantation grown Tectona grandis wood. Arch Appl Sci Res 2(6):113-120

19. Fuwape JA, Fabiyi JS (2003) Variations in strength properties of plantation grown Nauclea diderrichii wood. J Trop For Prod 9:45-53

20. Usta A, Yilmaz M, Kahveci E, Yilmaz S, Ozturk H (2014) Effects of different site conditions on some of the wood properties of Black alder (Alnus glutinosa (L.) Gaertner subsp. barbata (C.A Meyer) Yalt). Fresenius Environ Bull 23(8):1840-1851

21. Sharma SK, Rao RV, Shukla SR, Kumar P, Sudheendra R, Sujatha M, Dubey YM (2005) Wood quality of coppiced Eucalyptus tereticornis for value addition. IAWA J 26(1):137-147

22. Igartua DV, Moreno K, Piter JC, Monteoliva S (2015) Density and mechanical properties of Argentinean Acacia melanoxylon (in Spanish). Maderas Cienc Tecnol 17(4):809-820

23. Widmann R (2011) Grading of thermally modified beech. In: Proceedings of the 17th international nondestructive testing and evaluation of wood symposium, vol 1, pp 293-298

24. Johansson CJ, Steffen A, Wormuth EW (1996) Relation of moduli of elasticity in flatwise and edgewise bending of solid timber. In: International Council for Building Research Studies and Documentation, pp 311-321

25. Sales A, Candian M, Cardin VS (2011) Evaluation of the mechanical properties of Brazilian lumber (Goupia glabra) by nondestructive techniques. Constr Build Mater 25:1450-1454
26. Vazquez C, Goncalves R, Bertoldo C, Bano V, Vega A, Crespo J, Guaita M (2015) Determination of the mechanical properties of Castanea sativa Mill. using ultrasonic wave propagation and comparison with static compression and bending methods. Wood Sci Technol 49:607-622

27. Wang X, Ross RJ, McClellan M, Barbour RJ, Erickson JR, Forsman JW, McGinnis GD (2001) Nondestructive evaluation of standing trees with a stress wave method. Wood Fiber Sci 33(4):522-533

28. Posta J, Ptacek P, Jara R, Terebesyova M, Kuklik P, Dolejs $\mathrm{J}$ (2016) Correlations and differences between methods for non-destructive evaluation of timber elements. Wood Res 61(1):129-140

29. Oliveira FGR, Campos JAO, Sales A (2002) Ultrasonic measurements in Brazilian hardwood. Mater Res 5(1):51-55

30. Zhang SY, Zhong Y (1992) Structure-property relationship of wood in East-Liaoning oak. Wood Sci Technol 26:139-149

31. Hein PRG, Lima JT (2012) Relationships between microfibril angle, modulus of elasticity and compressive strength in Eucalyptus wood. Maderas Cienc Tecnol 14(3):267-274

32. Kamala FD, Sakagami H, Matsumura J (2014) Mechanical properties of small clear wood specimens of Pinus patula planted in Malawi. Open J For 4(1):8-13 